\title{
Periodical Maintenance of Forest Roads with a Mobile Stone Crusher
}

\author{
Gernot Erber, Huberta Kroisleitner, Christoph Huber, Thomas Varch, Karl Stampfer
}

\begin{abstract}
Forest road networks are exposed to damage by traffic, climate, timber harvesting and vegetation. To maintain their functionality, they must be maintained regularly. Periodical maintenance is required when the forest road surface layer is deteriorated and eroded. Well-graded material is required for replacing the forest road surface and often has to be sourced from gravel storage areas, which is costly and requires a large number of truck trips. Therefore, converting non-graded aggregate available on site into well-graded aggregate with a mobile stone crusher is considered a viable alternative.

The present study was carried out during a periodical maintenance treatment at the Bavarian State Forest Enterprise and the effect of employing a mobile stone crusher was evaluated with regard to (1) forest road load bearing capacity development during a one-year period posttreatment, (2) particle size distribution of the surface layer material before and after crushing, and (3) its cost compared to other alternatives. Samples were collected pre-and post-operation for particle size distribution analysis, load bearing capacity was measured repeatedly with a light falling weight deflectometer and compared to an untreated reference section and cost of the treatment was compared to two alternatives.

The mobile stone crusher was capable of reducing the non-graded to well-graded/close-to-wellgraded material and particle size distributions aligned well with the recommendations for lime-water bonded surfaces. Load bearing capacity exceeded the threshold of $40 \mathrm{MN} \mathrm{m}^{-2}$ ( $E_{v d}$ elastic modulus dynamic) for primary forest roads at all times. It increased significantly after the treatment and remained on a significantly higher level throughout the following year. Absolute and relative increases were higher than on the untreated reference section. The treatment variant involving a mobile stone crusher and material available on site was substantially cheaper $\left(5.31 € \mathrm{~m}^{-1}\right)$ than to supply non-graded $\left(16.29 € \mathrm{~m}^{-1}\right)$ or well-graded $\left(19.82 € \mathrm{~m}^{-1}\right)$ material by truck. Material and transport costs represented $67 \%$ and $82 \%$ of the total costs in the latter two cases. It can be concluded that mobile stone crushers are capable of producing at least close-to-well-graded forest road surface aggregate and that forest road load bearing capacity can be significantly and lastingly increased at only a part of the costs of the alternatives. A maximum of cost and resource efficiency and environmental soundness can be attained when enough surface aggregate is available on site. If this is not the case, sourcing nongraded material as local as possible is the next best alternative.
\end{abstract}

Keywords: particle size distribution, load bearing capacity, mobile stone crusher, forest road

\section{Introduction}

Forest road networks provide access to forest resources, enable transport of timber from the forest to the mill and are a prerequisite for efficient and sustainable forest management (Uusitalo 2010). They further provide access during disaster relief operations, are habitat to a wide variety of plant and animal species and serve for recreational purposes (BMLRT 2019).
Traffic (transport of goods and machinery, snowplowing, cattle drive), timber harvesting, climate (precipitation, melting water, frost, desiccation) and vegetation (above and on the road) are the main causes for damage to forest roads. Damages include (1) contamination (soil, foliage or excrements), (2) local damage (potholes, cracks and displacement), (3) wear of the surface layer or (4) structural damage to base and surface layers (Hirt 2001). 
The purpose of the surface layer is to absorb the shear stresses exerted by vehicle wheels, protect the base layer from penetration by rainwater and erosion by vehicle wheels and precipitation. Further, it ensures trafficability and traffic safety and drains off rainwater (Kuonen 1983). The forest road surface layer is eroded over time by heavy rains, which wash away small size particles and cause subsequent release and rolling away of coarser particles, and vehicle tires that dislodge and disperse the material. Further aggregate is lost during re-grading or due to bad practices, like extraction or processing of timber on the road (Ryan et al. 2004). In addition to that, aggregate is crushed and swiped of the forest road surface by traffic (Rhee et al. 2018). As a result, the thickness of the forest road surface layer, and consequently its load bearing capacity, decrease (Kuonen 1983, Ryan et al. 2004).

To preserve trafficability, traffic safety and structural integrity, forest roads have to be maintained regularly. Ongoing maintenance is carried out on demand (e.g. after heavy rainfalls), but at least once a year. Removing contamination and repair of local damages are typical activities. Periodical maintenance is required as soon as the forest road surface layer is worn off and eroded, thus not thick enough to bear the applied traffic loads, and typically at intervals of 6 to 12 years. It includes replacing and/or adding of surface layer aggregate and reshaping of the forest road surface (Hirt 2001, Ryan et al. 2004). If ongoing maintenance is carried out timely and properly, service life of the surface layer and the interval for periodical maintenance can be considerably extended (Dietz et al. 1984). Finally, the forest road might lack sufficient load bearing capacity altogether, as it had been designed for a lower frequency and intensity of traffic when it was constructed. To increase the load bearing capacity, additional surface layer aggregate must be applied (Kuonen 1983, Hirt 2001).

Strength, compatibility, water absorption capacity, frost sensitivity and workability of the material used in forest road construction are determined by its particle size distribution. The load bearing capacity of crushed, well-graded material is considerably higher than for non-graded material (Dietz et al. 1984). In most cases, well-graded material is not available on site and must be supplied over significant transport distances. For this reason, forest road surface layer construction is often the most expensive element of a forest road (Kramer 2001). The same applies to periodical maintenance, where supplying of additional material from external sources is the most expensive component (Maier 1991, Ryan et al. 2004).
Semi-mobile crushing plants and mobile stone crushers allow to convert non-graded material not suitable for construction of forest roads into well-graded material similar to that produced by stationary crushers in gravel storage areas (Fernsebner 1995, Gnanendran and Beaulieu 1999). As raw materials available on site or nearby can be used and do not have to be transported over long distances, this presents a cost- and resource-efficient and environmentally sound alternative to sourcing well-graded aggregate from gravel storage areas (Brossmann 1986, Stooss 1987, Stampfer 1991, Rohringer 1992, Bennet and Provencher 1995, Fernsebner 1995, Bassel 1998, Bassel and Clements 1998, Sheehy 2001).

Contrary to semi-mobile crushing plants, mobile stone crushers break up the material on the forest road and while moving. The workflow during a periodical maintenance treatment is the following: Firstly, the existing surface layer is ripped open with a grader, and suitable material from embankments and ditches is windrowed along the forest road centerline. In case that there is not enough material to ensure a sufficiently thick surface layer, further coarse, low-cost material can be added. It is then broken up by the mobile stone crusher and the desired road surface is produced by the grader and finally compacted by a roller (Fernsebner 1995).

The working principle of a mobile stone crusher is that of impact crushers, where the material to be crushed is broken up between a crushing bar and hammers arranged on rotor (Heuer et al. 1994). This is a power-hungry task. Therefore, mobile stone crushers require base machines equipped with a PTO-shaft and considerable engine output (Fernsebner 1995). Since their introduction in the 1980s, mobile stone crushers have been developed further in terms of functionality and reduction of wear and tear of the crusher and strain on the base machine. Today, mobile stone crushers are often designed as multi-purpose machines that can also include stone and stump grinding and mulching services (PTH 2020).

Though mobile stone crushers are frequently employed in forest road maintenance operations and considered a cost- and resource-efficient and more environmentally sound alternative to sourcing wellgraded material from a gravel storage area by truck, recent scientific literature on the subject is rare, and the investigation of mobile stone crushing treatments in terms of the effect of crushing on particle size distribution of the surface layer material, forest road load bearing capacity development after the treatment and cost of the treatment in comparison to other alternatives, is much less comprehensive. 
The goal of the present study thus was to evaluate the effect of a mobile stone crushing treatment with regard to (1) forest road load bearing capacity development during a one-year period post-treatment, (2) particle size distribution of the surface layer material before and after crushing, and (3) cost of the treatment in comparison to alternatives.

\section{Materials and Methods}

\subsection{Study Area}

The study area was located in the province of Bavaria in the German Alps and in the forest districts Jachenau and Kochl am See, both part of the Bavarian State Forest Enterprise, forest management unit Bad Tölz. It is part of the Northern Limestone Alps and limestone and dolomite form the bedrock in the study area. Three test sections (A to C) of 300 to $400 \mathrm{~m}$ length were selected along the $6730 \mathrm{~m}$ long Glaswald forest road, a road section built between 1970 and 1980, which was subjected to the maintenance treatment. A fourth test section $(R)$ was chosen as an untreated reference on a nearby forest road, comparable to the Glaswald forest road in age, design and maintenance history. Average terrain slope in test sections $\mathrm{A}$ to $\mathrm{C}$ was 35 to $45 \%$ and about $30 \%$ in the reference section R.

\subsection{Maintenance Treatment and Crushing Equipment}

The maintenance treatment was carried out on the total length of the Glaswald forest road between the end of September and mid-October 2015. On all sections, the so-called »Bachkies«, gravel from a river deposit, had been used for the forest road surface layer. In test section $\mathrm{A}$, enough surface material was available locally. Contrary, in sections B and C, the forest road surface layer was too worn to ensure sufficient pavement thickness and additional Bachkies gravel material had to be supplied from a gravel storage area. A MAN TGX 4-axle dump truck with a payload of 17 tons was used for transport and for depositing a 5 to $8 \mathrm{~cm}$ thick layer of non-graded material on the forest road. Surface layer and, in case of sections B and $C$, additional material were then windrowed along the forest road centerline by a 19-ton Caterpillar $14 \mathrm{H}$ motor grader with a blade width of $4.30 \mathrm{~m}$. Subsequently, the material was crushed with a PTH 2500 HD mobile stone crusher. Finally, the motor grader and a 12-ton Hamm 3412 oscillating smooth drum roller were employed to make and compact the forest road surface.

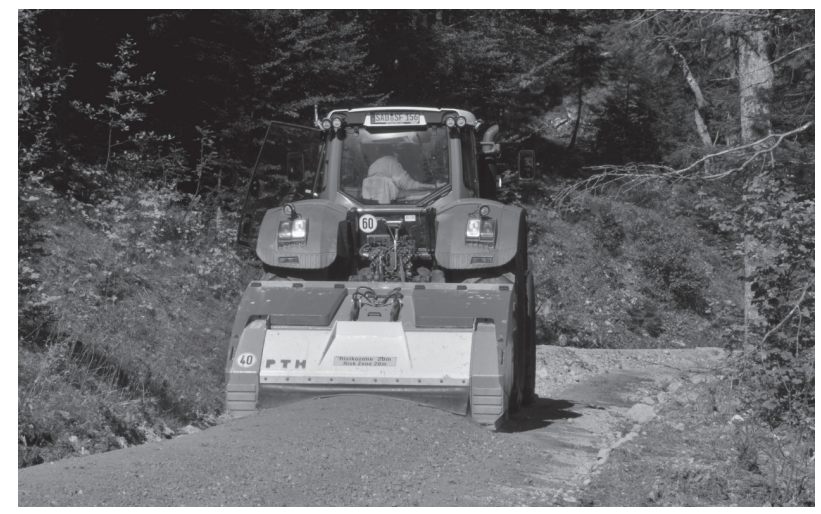

Fig. 1 »PTH Crusher 2500 HD« mounted on a Fendt 939 tractor crushing the windrowed ungraded material and leaving behind graded forest road surface layer material

The PTH 2500 HD mobile stone crusher (Fig. 1) has a net weight of $6250 \mathrm{~kg}$ and a working width of $2.5 \mathrm{~m}$. It requires a base machine with a PTO-shaft and a minimum engine power of $191 \mathrm{~kW}$. Travel speed during operation is 0.3 to $0.4 \mathrm{~km} \mathrm{~h}^{-1}$. During the study, it was mounted on a 10-ton Fendt 939 tractor with an engine power of $265 \mathrm{~kW}$. The material to be crushed can be picked up from a depth of up to $0.35 \mathrm{~m}$ below surface and is broken up between a crushing bar and 32 hammers arranged on a $1550 \mathrm{~kg}$ rotor. The desired particle size distribution is attained through adjusting the spacing between hammers and crushing bar (10 to $70 \mathrm{~mm}$ ) and rotor rotation speed. The crusher is designed to process material up to a hardness of 200 to $250 \mathrm{~N} \mathrm{~m}^{-2}$. The harder the material, the more often the hammers and the crushing bar must be replaced. At a hardness of 80 to $110 \mathrm{~N} \mathrm{~m}^{-2}$, their durability is about 200 working hours, and around 100 working hours at a hardness of up to $160 \mathrm{~N} \mathrm{~m}^{-2}$. Hard metal protection plates are available to reduce rotor wear.

\subsection{Load Bearing Capacity Monitoring}

Soil bearing capacity is a characteristic that aids the decision whether a forest road is in need of periodical maintenance, as visual assessment alone does not always allow a clear decision (Hirt 2001, Kaakkurivaara et al. 2015). Further, daily measurements in the thawing period allow to determine if the road is trafficable at the moment or if it has to be closed for traffic (Kaakkurivaara et al. 2015). Soil bearing capacity is defined as the ability to bear a given load without excessive deformation (Giudicetti 1968). Excessive deformation refers to irreversible consolidation and plastic deformations (Dietz et al. 1984). Soils of higher bearing capacity are deformed more slowly and to a 
lesser extent than soils with a low bearing capacity (Kuonen 1983). Falling weight deflectometers (FWD), dynamic cone penetrometers (DCP) and light weight falling deflectometers (LWFD) are the most common tools for measuring load bearing capacity. While FWDs are cumbersome tools, usually mounted on a trailer, DCPs and LFWDs are easily portable, less expensive and faster and easier to use than the former ones (Kaakkurivaara et al. 2015). LWFDs were originally designed to verify the compaction and bearing capacity of soils during earthwork and pavement construction, but have proven to be capable of accurate measuring on gravel- and asphalt surface roads, too (Steinert et al. 2005). Kaakkurivaara et al. (2015) conducted a comparative study of FWD, DCP and LFWD measurements on forest roads and concluded that LFWDs and DCPs constitute reasonably reliable substitutes for FWD measurements and are suitable for determining trafficability and the need for maintenance or rehabilitation of forest roads.

LWFD measurement is based on the momentary deformation of the ground surface. In the present study, a TerraTest 3000 GPS LFWD was employed, which has proven to be a reliable tool for this purpose in several other studies (Bohrn et al. 2014, Fichtinger
2014, Fritz 2019, Riegler 2019). For measuring the momentary deformation of the ground surface, a $10 \mathrm{~kg}$ weight is dropped on a $300 \mathrm{~mm}$ wide circular loading plate from a height of $1140 \mathrm{~mm}$. Thereby, an impulse of 7.07 $\mathrm{MN}$ is generated and the force is gauged during the calibration to ensure a normal tension of $0.1 \mathrm{MN} \mathrm{m}^{-2}$. Through deflection sensors mounted on the load plate, the deformation of the pavement in response to the load is measured. Prior to the actual measurement, the weight has to be dropped three times for levelling the loading plate on surface. During three further drops, the deformation of the surface in response to the load is measured, averaged and converted to elastic modulus, deflection module or load bearing capacity $\left(\mathrm{E}_{\mathrm{vd}}\right.$, elastic modulus dynamic; $\mathrm{MN} \mathrm{m}^{-2}$ ). In addition, the record of each measurement point includes consolidation extent $(\mathrm{mm})$ and speed $\left(\mathrm{mm} \mathrm{s}^{-1}\right)$, as well as descriptive parameters (GPS location, timestamp). Records can be printed, accessed on the LWFD display or through connecting it to a computer via cable or a smartphone via Bluetooth. Principally, the TerraTest 3000 GPS can be used for any type of road construction operation. However, the use is limited by the maximum particle size, which shall not exceed $63 \mathrm{~mm}$. Its maximum measurement depth is $60 \mathrm{~cm}$. It is equipped with a

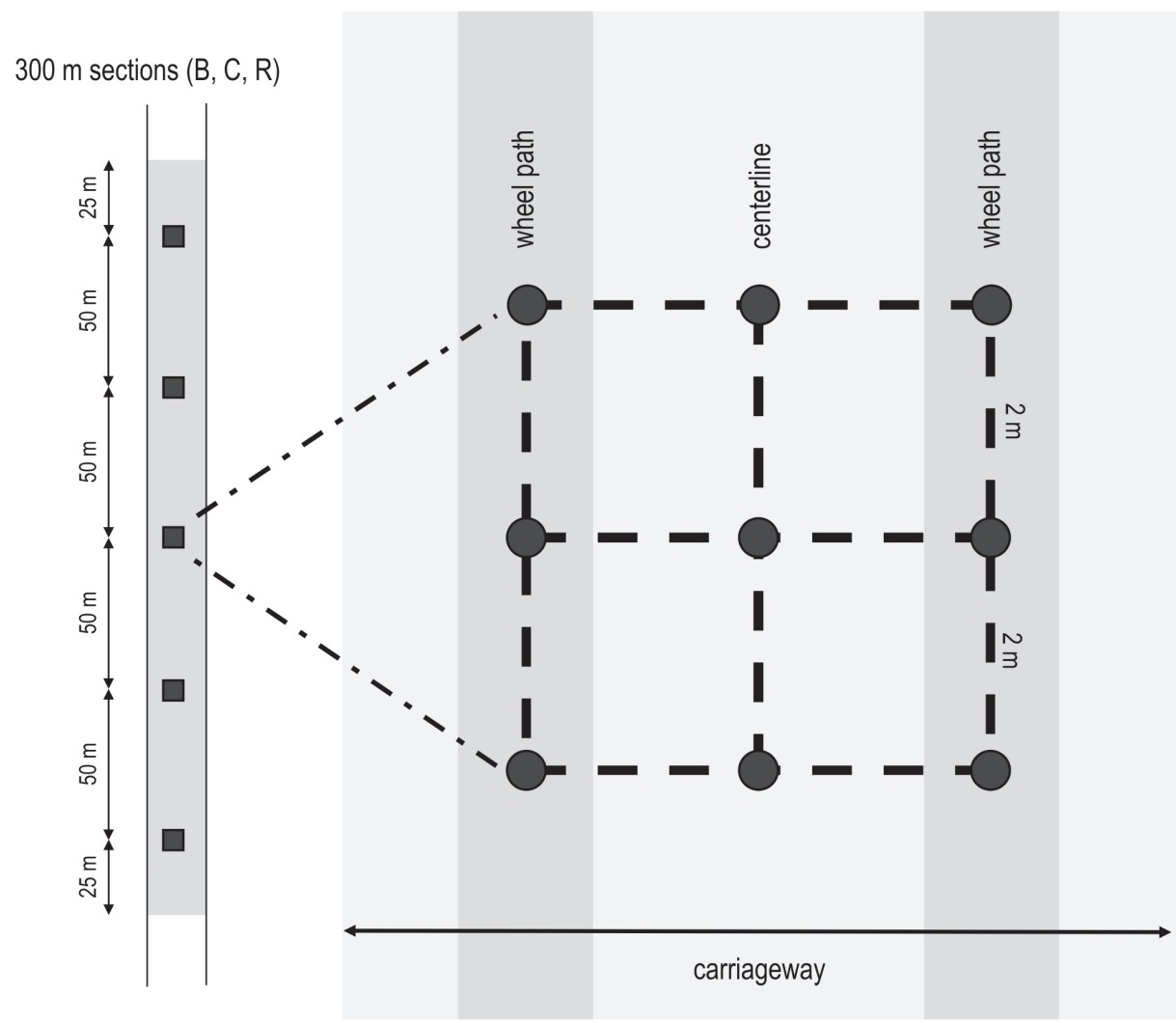

400 m section $(A)$

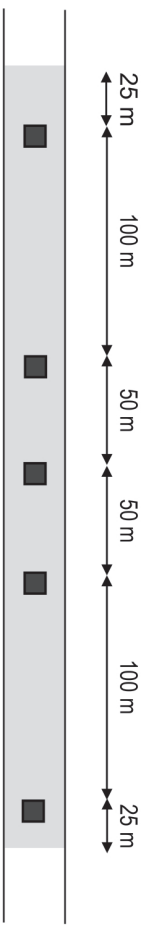

Fig. 2 Measurement spacing of forest road load bearing capacity on $300 \mathrm{~m}$ and $400 \mathrm{~m}$ test sections and layout on sample points 
rechargeable battery and can be transported between measurement points on dedicated vehicle similar to a hand-truck, which significantly reduces physical strain for the person conducting the measurements (TerraTest 2009).

Load bearing capacity measurements were conducted right before and after the maintenance treatment in September and November 2015, and in May, July and November 2016. Within each test section, five test sections were established (Fig. 2). These were distributed at $50 \mathrm{~m}$ intervals in $300 \mathrm{~m}$ sections (B, C and $\mathrm{R})$, while two $100 \mathrm{~m}$ intervals were added in the $400 \mathrm{~m}$ test section (A). Each sample section comprised of nine single measurement points arranged in a square network fashion with three measurement points spaced about $2 \mathrm{~m}$ on the road centerline and on each wheel path. Centerline and wheel path measurements had to be spaced at least $50 \mathrm{~cm}$ apart. To avoid erroneous results due to compaction of sample points, test sections were shifted along the forest road between measurement dates to avoid repeated sampling of the same measurement point. Test sections were also shifted if located above a drainage pipe.

Load bearing capacity data was exported via the TerraTest software to a PC and checked for completeness, consistency and plausibility. Descriptive statistics and graphs were prepared in Microsoft Excel. Statistical analysis (Scheffe-test, ANOVA, $t$-test) of load bearing capacity development over time was carried out with the statistical software IBM SPSS Statistics 21 , and an alpha level of 0.05 was used throughout the study. To be considered acceptable in terms of load bearing capacity, the load bearing capacity limit for primary forest roads traversed by standard timber transport trucks with a gross vehicle weight of up to 40 tons (40 $\mathrm{MN} \mathrm{m}^{-2} \mathrm{E}_{\mathrm{vd}}$; elastic modulus, dynamic; Kuonen 1983, Dietz et al. 1984) had to be exceeded.

For better interpretability of load bearing capacity development, meteorological data was sourced from the German National Meteorological Service (DWD) for the period of September 2015 to November 2016 from local meteorological stations. Air temperature data was retrieved from the Mittelwald-Buckelwiese station $(18.9 \mathrm{~km}$ from the study site, $981 \mathrm{~m}$ above sea level) and precipitation data from the Jachenau-Tannern station $(6.7 \mathrm{~km}$ from the study site, $720 \mathrm{~m}$ above sea level).

\subsection{Particle Size Distribution Sampling and Analysis}

Particle size distribution sampling and analysis were conducted in accordance with OENORM EN ISO 17892-4 (2017). Samples were taken from the wind- rowed material on test sections $\mathrm{A}$ and $\mathrm{B}$ before and after crushing and from the additional material supplied to section B. On each of the load bearing measurement intervals, a sample was collected. Each was composed of a mix of wheel path and centerline material collected along a cross-section of the piled material. Samples were taken with a shovel, sealed into buckets with a lid and provided with an ID.

Particle size distribution analysis included dry- and wet sieving and a sedimentation analysis. Particle size fraction masses were entered into a Microsoft Excel spreadsheet. From this data, particle size distribution curves were created and compared to optimum particle size distribution for lime-water bonded pavements (Kuonen 1983). Particle size distributions are described by Fuller-curves (Fuller and Thompson 1907), which are parabolic in shape and include an exponent e that describes the particle shape. For a low void mixture, such as gravel, e lies between 0.40 and 0.55 (Kuonen 1983). Particle size distributions were further described by their median $\left(\mathrm{d}_{50}\right)$ and mean particle sizes. Finally, the material suitability for construction purposes was classified according to DIN 18196 (2011).

\subsection{Cost Calculation}

Maintenance treatment costs were calculated for the Glaswald forest road total length of $6730 \mathrm{~m}$ and three different scenarios. In scenario A, no additional material is required. Contrarily, in scenarios B and C additional material is brought in. In case of $B$, it is nongraded material (all grain sizes and natural grain size distribution), while it is crushed, well-graded gravel material (0 to $32 \mathrm{~mm}$ grain size), with a grain size distribution suitable for forest road surface layer construction without further need for crushing in C. The required volume of additional material was obtained by weighing cross-segments of windrowed material after the crushing treatment. The additional material is sourced from a local gravel storage area at costs of $9.20 € \mathrm{t}^{-1}$ for the non-graded and $12.70 € \mathrm{t}^{-1}$ for the wellgraded material (Rohrdorfer 2018). Transport is conducted with a 4-axle dump truck. A motor grader is employed for windrowing the local and supplied surface layer material and for grading of the forest road in all scenarios. The material is crushed by the stone crusher in scenarios A and B, but not in C. In all scenarios, a vibrating roller is used for compaction of the surface layer. System productivity (meters per productive system hour including delays up to $15 \mathrm{~min}$; $\mathrm{m} \mathrm{PSH}_{15}{ }^{-1}$ ) and cost (Euro per productive system hour including delays up to $15 \mathrm{~min}$; $€ \mathrm{PSH}_{15}{ }^{-1}$ ) for all machines were obtained from long-term records of the Bavarian State Forest Enterprise (Table 1). 
Table 1 Maintenance treatment cost for variants A to C. Total costs are calculated for the Glaswald forest road length of $6730 \mathrm{~m}$

\begin{tabular}{|c|c|c|c|c|c|}
\hline Item & Parameter & Unit & Scenario A & Scenario B & Scenario C \\
\hline \multirow{6}{*}{ Material } & Supplied material type & - & - & non-graded & well-graded \\
\hline & Cost & $€ \mathrm{t}^{-1}$ & - & 9.20 & 12.70 \\
\hline & Demand & $\mathrm{t} \mathrm{m}^{-1}$ & - & 0.55 & 0.7 \\
\hline & Cost & $€ \mathrm{~m}^{-1}$ & - & 5.06 & 8.89 \\
\hline & Total demand & $\mathrm{t}$ & - & 3503.5 & 4459.0 \\
\hline & Total cost & $€$ & - & $32,232.20$ & $56,629.30$ \\
\hline \multirow{9}{*}{ Truck transport } & Distance (back and forth) & $\mathrm{km}$ & - & \multicolumn{2}{|c|}{80} \\
\hline & Average speed & $\mathrm{km} \mathrm{h}^{-1}$ & - & \multicolumn{2}{|c|}{50} \\
\hline & Payload & $\mathrm{t}$ & - & \multicolumn{2}{|c|}{17} \\
\hline & Loading/Unloading time consumption & $\mathrm{PSH}_{15}$ & - & \multicolumn{2}{|c|}{1} \\
\hline & Driving time consumption & $\mathrm{PSH}_{15}$ & - & \multicolumn{2}{|c|}{1.6} \\
\hline & Cost & $€ \mathrm{PSH}_{15}{ }^{-1}$ & - & \multicolumn{2}{|c|}{70.00} \\
\hline & Cost & $€$ load $^{-1}$ & - & \multicolumn{2}{|c|}{182.00} \\
\hline & Total loads & $\mathrm{n}$ & - & 207 & 263 \\
\hline & Total cost & $€$ & - & $37,674.00$ & $47,866.00$ \\
\hline \multirow{4}{*}{ Grading (windrowing material) } & Productivity & $\mathrm{mPSH}{ }_{15}^{-1}$ & \multicolumn{3}{|c|}{116} \\
\hline & Total time consumption & $\mathrm{PSH}_{15}$ & \multicolumn{3}{|c|}{54.9} \\
\hline & Cost & $€ \mathrm{PSH}_{15}{ }^{-1}$ & \multicolumn{3}{|c|}{95.00} \\
\hline & Total cost & $€$ & \multicolumn{3}{|c|}{5216.18} \\
\hline \multirow{4}{*}{ Crushing } & Productivity & $\mathrm{mPSH}{ }_{15}{ }^{-1}$ & \multicolumn{2}{|c|}{179} & - \\
\hline & Total time consumption & $\mathrm{PSH}_{15}$ & \multicolumn{2}{|c|}{35.6} & - \\
\hline & Cost & $€ \mathrm{PSH}_{15}{ }^{-1}$ & \multicolumn{2}{|c|}{340.00} & - \\
\hline & Total cost & $€$ & \multicolumn{2}{|c|}{$12,099.44$} & - \\
\hline \multirow{4}{*}{ Grading (creating surface) } & Productivity & $\mathrm{mPSH}{ }_{15}{ }^{-1}$ & \multicolumn{3}{|c|}{63.00} \\
\hline & Total time consumption & $\mathrm{PSH}_{15}$ & \multicolumn{3}{|c|}{101.1} \\
\hline & Cost & $€ \mathrm{PSH}_{15}{ }^{-1}$ & \multicolumn{3}{|c|}{95.00} \\
\hline & Total cost & $€$ & \multicolumn{3}{|c|}{9605.56} \\
\hline \multirow{4}{*}{ Compaction } & Productivity & $\mathrm{mPSH}{ }_{15}{ }^{-1}$ & \multicolumn{3}{|c|}{69.00} \\
\hline & Total time consumption & $\mathrm{PSH}_{15}$ & \multicolumn{3}{|c|}{92.32} \\
\hline & Cost & $€ \mathrm{PSH}_{15}{ }^{-1}$ & \multicolumn{3}{|c|}{75.00} \\
\hline & Total cost & $€$ & \multicolumn{3}{|c|}{6923.91} \\
\hline & & $€$ & $33,845.72$ & $103,751.92$ & $126,241.58$ \\
\hline Iuld cust & & $€ \mathrm{~m}^{-1}$ & 5.31 & 16.29 & 19.82 \\
\hline
\end{tabular}

\section{Results}

\subsection{Forest Road Load Bearing Capacity}

On test sections $\mathrm{A}$ to $\mathrm{C}$, the load bearing capacity exceeded the $40 \mathrm{MN} \mathrm{m}^{-2}$ threshold before the treatment in September 2015, and average load bearing capacity ranged from 47.1 to $58.7 \mathrm{MN} \mathrm{m}^{-2}$ (Fig. 3). On the reference section $\mathrm{R}$, a load bearing capacity of 75.1 $\mathrm{MN} \mathrm{m}^{-2}$ was observed. Two months later, and after the maintenance treatment, the load bearing capacity increased considerably on all test sections. An increase to more than double (plus 112 to $120 \%$ ) the previous load bearing capacity was observed on test 


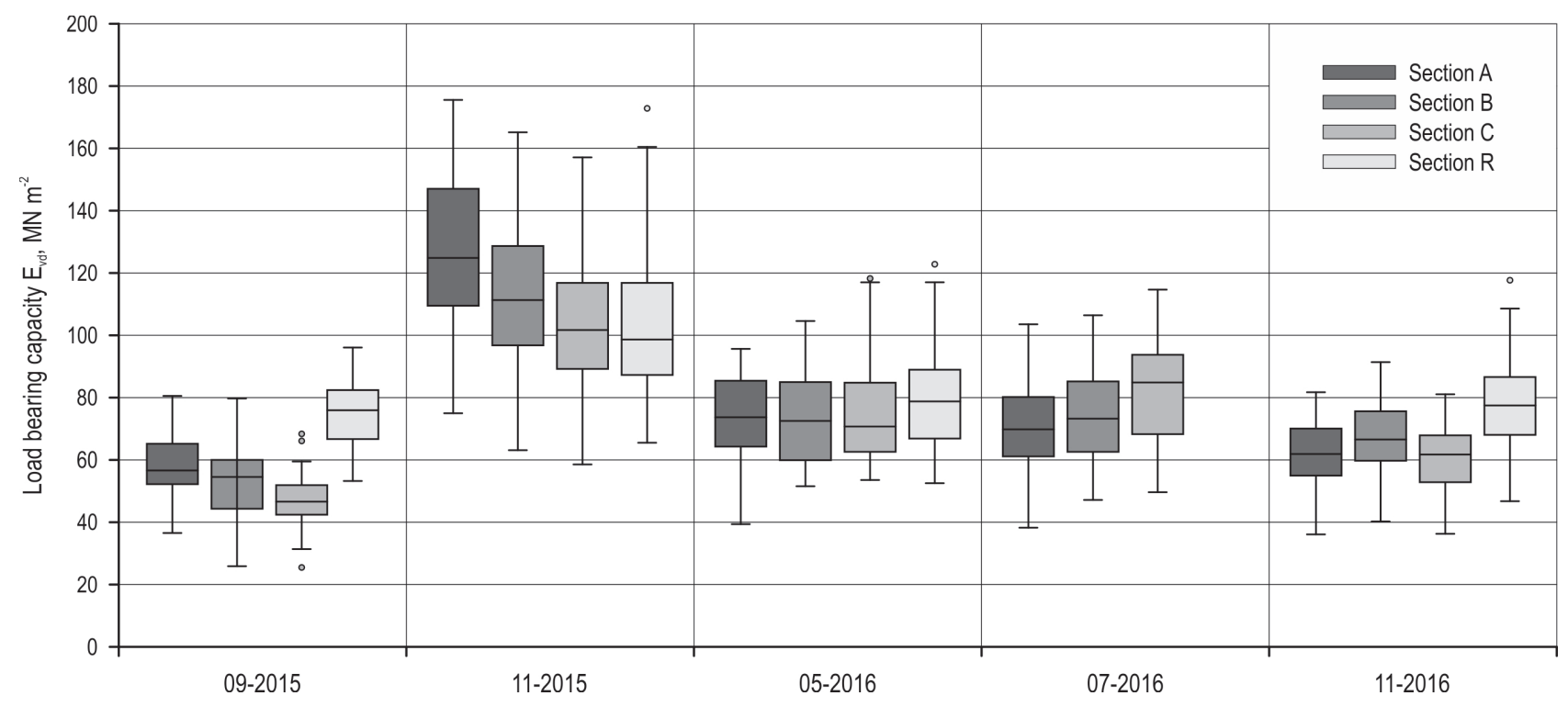

Fig. 3 Forest road load bearing capacity pre-treatment (September 2015) and development post-treatment. In July 2016, no load bearing capacity measurement was conducted on reference section $\mathrm{R}$ due to technical problems

sections A to $\mathrm{C}\left(103.8\right.$ to $\left.125.9 \mathrm{MN} \mathrm{m}^{-2}\right)$, while a more modest increase of $40 \%$ was observed on the untreated section $\mathrm{R}\left(103.7 \mathrm{MN} \mathrm{m}^{-2}\right)$. Eight and ten months after the treatment, in May and June 2016, the average load bearing capacity in sections A to C (72.6 to $75.1 \mathrm{MN} \mathrm{m}^{-2} ; 71.1$ to $82.0 \mathrm{MN} \mathrm{m}^{-2}$ ) was statistically significantly above the initial levels (plus 24 to $59 \%$ and 21 to $74 \%$ ). For comparison, the load bearing capacity on reference section $\mathrm{R}\left(80.2 \mathrm{MN} \mathrm{m}^{-2}\right)$ was $7 \%$ above the level of September 2015 and May 2016. More than one year after the treatment, in November 2016, the average load bearing capacity on sections A to $\mathrm{C}$ was 61.6 to $66.9 \mathrm{MN} \mathrm{m}^{-2}$ or 5 to $29 \%$ above the pre-treatment level. Only in case of section A, this was not statistically significant. At the same time, the average load bearing capacity on section $\mathrm{R}$ was 77.9 MN $\mathrm{m}^{-2}$ and $4 \%$ higher than in September 2015. The comparison of load bearing capacity between forest road centerline and wheel paths revealed no statistically significant differences on sections $B$ and $R$, in only occasional differences on sections A and C, typically between wheel path(s) and road centerline. No statistically significant differences were observed between wheel paths.

\subsection{Particle Size Distribution}

Pre-treatment particle size distribution in locally available, windrowed material on section A (Fig. 4) was characterized by a prevalence of coarse particles (gravel and stone aggregates). The crushing treatment reduced the $\mathrm{d}_{50}$ by about half from $9.61 \mathrm{~mm}$ to $4.85 \mathrm{~mm}$ and the size of the largest particle from $112 \mathrm{~mm}$ to $31.5 \mathrm{~mm}$. The size of particles was reduced considerably in particle size fractions above $0.5 \mathrm{~mm}$ and led to a much better alignment with the distribution recommended by Kuonen (1983) for lime-water bonded surface layers. The material was classified as skip-graded gravel-sand mix, with good suitability for earth and construction roads.

On section B (Fig. 5), samples had been taken from the material supplied and the windrowed mix of supplied and locally available material, and from the latter on two subsequent days. The close alignment of supplied and mixed material particle size distributions indicated that only a small share of the material stemmed from material locally available, thereby confirming the need for additional supply. Similar to section $\mathrm{A}$, the crushing treatment clearly enhanced particle size distribution and resulted in close alignment with Kuonen's (1983) recommendations. The $d_{50}$ of the supplied material was $26.7 \mathrm{~mm}$, and it was $29.7 \mathrm{~mm}$ and $28.8 \mathrm{~mm}$ for the mixes of both days. Through crushing, it was reduced to $6.2 \mathrm{~mm}$ and $3.2 \mathrm{~mm}$. Contrarily to section $\mathrm{A}$, the crushed material featured a small share of larger gravel aggregate in both and fine fractions (silt to sand) the second day, while the share of the sand to gravel fraction was a little below prescription for the mix of the first day. The size of the largest particles was reduced from $114 \mathrm{~mm}$ and $112 \mathrm{~mm}$ to $63 \mathrm{~mm}$ in both cases. Crushing produced skip-graded material, which was classified and suited for the construction of earth and construction roads. 


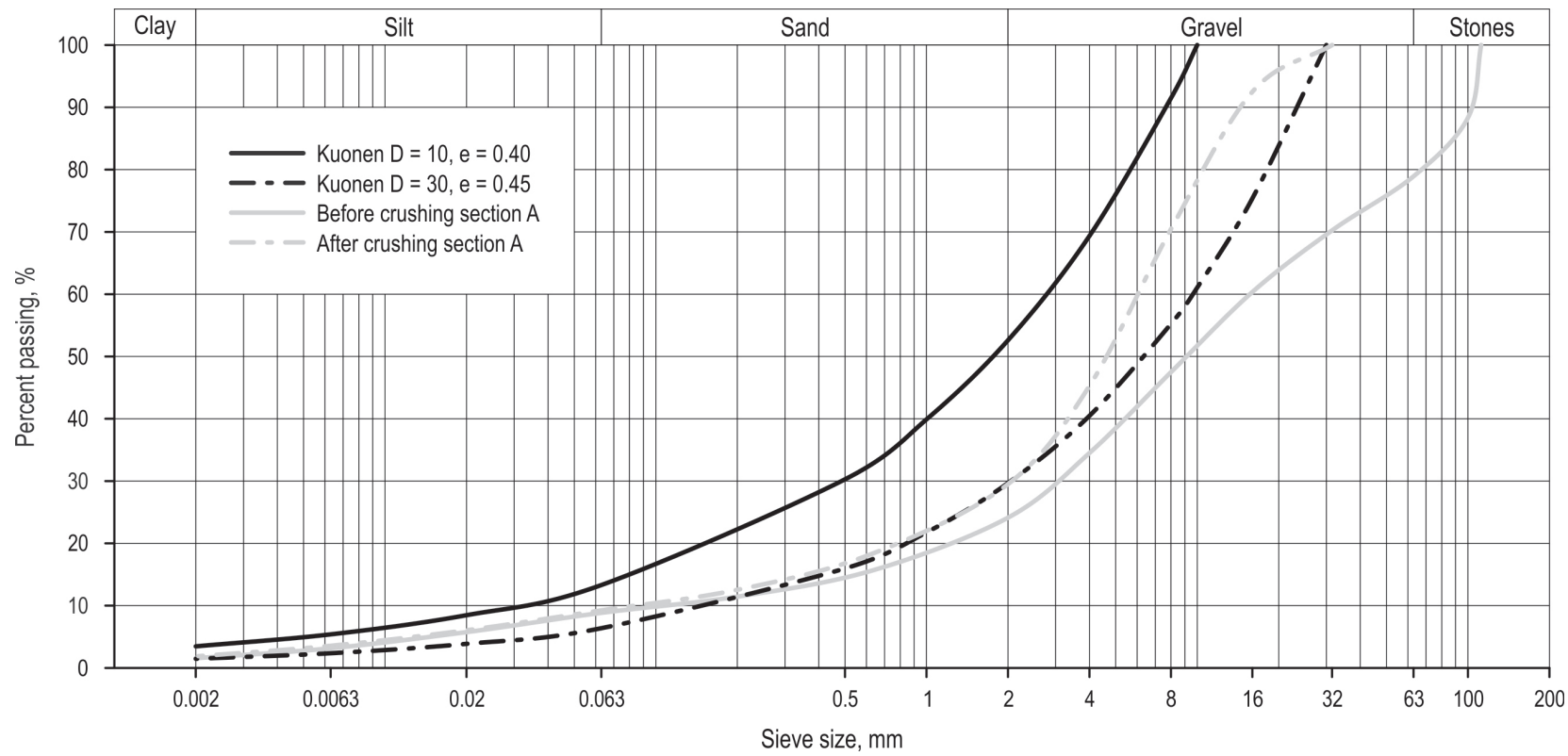

Fig. 4 Particle size distribution before and after crushing treatment on test section A. After the treatment it showed a much better alignment with Kuonen's (1983) recommendations for lime-water bonded surface layers

\subsection{Maintenance Treatment Cost}

Conducting the maintenance treatment with material available on site (scenario A) was substantially cheaper than in the scenarios where non-graded (B) or well-graded material (C) was supplied (Table 1, Fig. 6).
The total cost of scenario A corresponded to 33\% (B) and $27 \%(C)$ of that of the others. High costs of the latter are explained by material and transport costs, which were the main cost item in both cases and represented about $67 \%$ and $82 \%$ of the total costs.

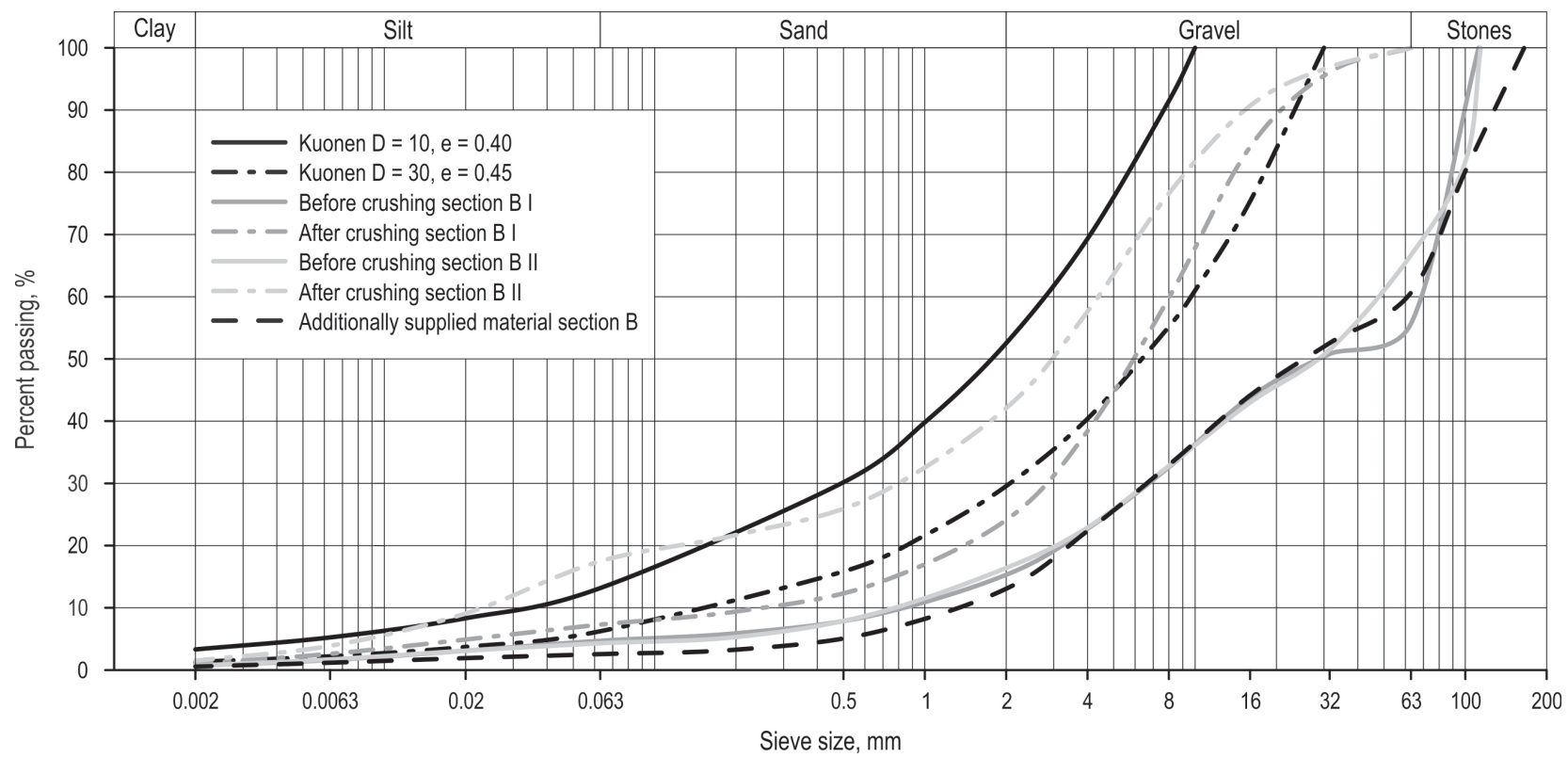

Fig. 5 Particle size distribution before and after crushing treatment on test section B. Samples were taken from additionally supplied material and on two days from the mix of the supplied and locally available material before and after crushing. After the treatment, it showed a much better alignment with Kuonen's (1983) recommendations for lime-water bonded surface layers 


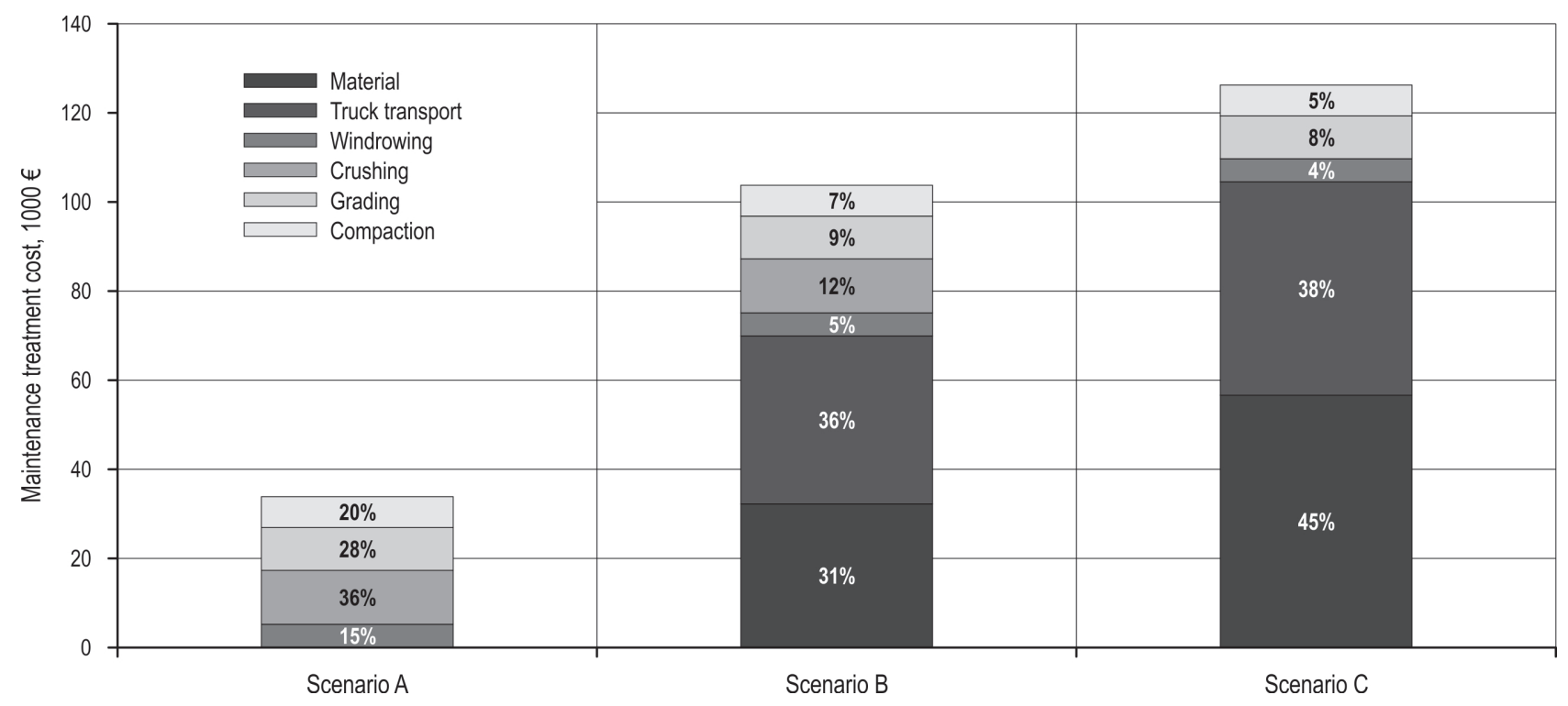

Fig. 6 Cost components of maintenance treatment for scenarios $A$ to $C$

\section{Discussion}

For the first time, periodical maintenance with a mobile stone crusher was investigated with regard to its effect on the aggregate particle size distribution of the surface layer in combination with monitoring the post-treatment of forest road load bearing capacity development over one year. Further, its cost was compared to alternative treatments involving supply of additional material.

The mobile stone crusher was capable of improving surface layer material characteristics and reducing the coarse, non-graded raw material to at least closeto-well-graded material suitable for constructing forest road surface layers on both investigated sections. On section $\mathrm{B}$, the maximum particle size was larger than recommended by Kuonen (1983) for lime-water bonded surface layers. However, mass share of oversized particles was small with less than $4 \%$ in total. One more pass by the mobile stone crusher might have been necessary to reduce these particles to the required size.

Forest road load bearing capacity increased significantly on all test sections and on the reference section immediately after the treatment. Some of this effect may have to be attributed to 14 days of dry weather with only $3.2 \mathrm{~mm}$ of precipitation and setting in of frost with daily temperature minima below $0{ }^{\circ} \mathrm{C}$ before the measurements in November 2015. Contrary to the reference section, the load bearing capacity remained on a significantly higher level on the test sections throughout 2016, thus indicating that the treat- ment had truly increased it. Only on section A, the load bearing capacity did drop to almost the pre-treatment level in November 2016, which might be explained by timber harvesting and transport activities during that period, which resulted in rutting and deformation of the road surface in combination with daily mean air temperature alternating between minus and plus degrees. Unfortunately, no load bearing capacity measurements were conducted during springtime and thus the anticipated drop in springtime, as described by Burlet (1980), is not documented. In contrast to Fichtinger (2014), no continuously significant differences were observed between wheel path and centerline load bearing capacity. This probably can be explained by the fact that, contrary to this study, no vegetation covered the centerline and that the test sections were not subjected to heavy traffic to an extent that would cause such a disparity.

In accordance with previous investigations of Fernsebner (1995), Bassel and Clements (1998) and Sheehy (2001), the mobile crusher variant involving raw material available on site was the most cost-efficient variant by far. Material and transport activities accounted for most of the costs in variants B and C (68\% and 83\%) and were thus in the same range as observed by Maier (1991) for maintenance operations of the Austrian Federal Forests. Therefore, working with material available on site is preferable. If this is not possible, material should be sourced as locally as possible to keep transport distances and costs low. For example, if the transport distance can be reduced from $80 \mathrm{~km}$ to $10 \mathrm{~km}$ (back and forth), transport cost can be reduced 
by more than $50 \%$ and total costs by about $20 \%$. If the material can be sourced from a gravel pit of the forest enterprise, the total cost can be decreased by about $31 \%$ at $80 \mathrm{~km}$ transport distance and by more than $50 \%$ at $10 \mathrm{~km}$ distance. It is assumed here that loading is done with the truck bucket grapple. If a loader $\left(93 € \mathrm{PSH}_{15}{ }^{-1}\right)$ is taken into account and under the assumption that loading takes $50 \%$ of the total loading and unloading time, the total cost decrease by about $22 \%$ for the long and $43 \%$ for the short transport distance. As shown by Stampfer (1991), the difference between variants B and C can be small, if the cost difference between wellgraded and non-graded material is marginal and equals the costs of crushing, and thus the employment of mobile stone crushers has to be evaluated case by case.

\section{Conclusions}

Mobile stone crushers are capable of producing at least close-to-well-graded forest road surface aggregate and forest road load bearing capacity can be significantly and lastingly increased at only a part of the costs of the alternatives. A maximum of cost- and resource efficiency and environmental soundness can be attained when enough raw material is available on site. If this is not the case, sourcing non-graded material as local as possible is the next best alternative.

\section{Acknowledgments}

No specific funding was received for this work. The authors would like to thank the Bavarian State Forest Enterprise, represented by Armin Haberl and his team, and the company Profi-Team-Holzer for enabling the study and providing support during the field work.

\section{References}

Bassel, J.R., 1998: A comparison of two road reconditioning systems: Roto Trimmer and Forester C-2000. USDA Forest Service, San Dimas Technology and Development Center, California, U.S.A., 13 p.

Bassel, J.R., Clements, S., 1998: Forester C-2000 road reconditioning: 3 demonstration projects. USDA Forest Service, San Dimas Technology and Development Center, California, U.S.A., 13 p.

Bennett, D.M., Provencher, Y., 1995: Using mobile rockcrushing equipment to rehabilitate unpaved forest road surfaces - Recent developments in Canada. Proceedings of the 6th International Conference on Low Volume Roads Vol. 1., Minneapolis, Minnesota, U.S.A., June 25-29. Transportation
Research Board, National Research Council, National Academy Press: Washington D.C., U.S.A., 248-253.

Bohrn, G., Stampfer, K., 2014: Untreated Wood Ash as a Structural Stabilizing Material in Forest Roads. Croatian Journal of Forest Engineering 35(1): 81-89.

Federal Ministry of Agriculture, Regions and Tourism (BMLRT), 2019: Forststrassen - Lebensadern des Waldes [Forest roads - Lifelines of the forest]. Available online: https://www.bmlrt.gv.at/forst/oesterreich-wald/oekosystem/forststrasse.html (accessed March 06, 2020)

Brossmann, L., 1986: Der Steinbrecher, ein Mehrzweck-Gerät für Forstbetriebe [The stone crusher, a multi-purpose machine for forest enterprises]. Allgemeine Forstzeitschrift 41 (25/26): 624-626.

Burlet, E., 1980: Dimensionierung und Verstärkung von Strassen mit geringem Verkehr und flexiblem Oberbau [Dimensioning and reinforcement of roads with low traffic and flexible superstructure]. PhD thesis. Eidgenössische Technische Hochschule, Zürich, Switzerland.

Dietz, P., Knigge, W., Löffler, H., 1984. Walderschließung: Ein Lehrbuch für Studium und Praxis unter besonderer Berücksichtigung des Waldwegebaus [Opening up the forest: A textbook for study and practice with a special focus on forest road construction]. Parey: Hamburg/Berlin, Germany, $426 \mathrm{p}$.

DIN 18196, 2011: Earthworks and foundations - Soil classification for civil engineering purposes. Beuth Verlag, Berlin, Germany, $13 \mathrm{p}$.

Fernsebner, N., 1995: Schotteraufbereitung mit halbstationären und mobilen Steinbrechern für den Neubau und die Instandhaltung von Forststraßen [Gravel processing with semi-mobile and mobile stone crushers for the construction and maintenance of forest roads]. Centralblatt für das gesamte Forstwesen 112(2): 71-80.

Fichtinger, C., 2014: Analyse der forstlichen Erschließungssituation und Tragfähigkeit von Forststraßen im Bezirk Hermagor (Kärnten) [Analysis of the forest road network and load bearing capacity of forest roads in the Hermagor (Carinthia) district]. Master thesis, University of Natural Resources and Life Sciences, Vienna, Austria.

Fritz, M.J., 2019: Wassergehalt im Forststraßenkörper und dessen Auswirkungen auf die Tragfähigkeit [Moisture content in the forest road body and its effect on bearing capacity]. Master thesis, University of Natural Resources and Life Sciences, Vienna, Austria.

Fuller, W.B., Thompson, S.E., 1907: The laws of proportioning concrete. Transactions of the American Society of Civil Engineers 33(2): 222-298.

Giudicetti, F., 1968: Die Befahrbarkeit natürlicher Böden [Trafficability of natural soils]. Zürich: Mitteilungen der Versuchsanstalt für Wasserbau und Erdbau 77: Zürich, Switzerland.

Gnanendran, C.T., Beaulieu, C., 1999: On the behaviour of low-volume unpaved resource access roads: effects of reha- 
bilitation. Canadian Journal of Civil Engineering 26(3): 262269. https://doi.org/10.1139/cjce-26-3-262

Hirt, R., 2001: Erschließungsanlagen II. Strassen und Maschinenwege: Bemessung, Instandhaltung, Erneuerung. Unterlagen zur Vorlesung Forstlichen Ingenieurwesen [Opening up II. Roads and machine paths: Dimensioning, maintenance, reconstruction. Materials of the lecture Forest Engineering]. Eidgenössische Technische Hochschule, Zürich, Switzerland.

Heuer, G., Gubany, J., Hindrichsen, G.,1999: BaumaschinenTaschenbuch: Ratgeber für die Baupraxis. Bauverlag $\mathrm{GmbH}$ : Wiesbaden/Berlin, Germany, 345 p.

ÖNORM EN ISO 17892-4, 2017: Geotechnical investigation and testing - Laboratory testing of soil - Part 4: Determination of particle size distribution. Austrian Standards: Vienna, Austria, 41 p.

Profi Team Holzer (PTH), 2020: PTH products [online]. Available online: http://www.pthproducts.com/en/ (accessed 16 Mar 2020).

Kaakkurivaara, T., Vuorimies, N., Kolisoja, P., Uusitalo, J., 2015: Applicability of portable tools in assessing the bearing capacity of forest roads. Silva Fennica 49(2): 1-26. https://doi. org/10.14214/sf.1239

Kuonen, V., 1983: Wald- und Güterstraßen: Projektierung, Planung, Bau [Forest and agricultural roads: Project planning, design, construction]. Self-published: Pfaffhausen, Switzerland, $743 \mathrm{p}$.

Kramer, B.W., 2001: Forest road contracting, construction, and maintenance for small forest woodland owners. Forest Research Laboratory, Oregon State University: Corvallis, Oregon, U.S.A., Research Contribution 35, 84 p.

Maier, G., 1991: Kosten und Technik der Forststraßeninstandhaltung und -instandsetzung bei den Österreichischen Bundesforsten [Costs and technology of forest road maintenance and repair at the Austrian Federal Forests]. Master thesis, University of Natural Resources and Life Sciences, Vienna, Austria.

Rhee, H., Fridley, J., Page-Dumroese, D., 2018: Traffic-Induced Changes and Processes in Forest Road Aggregate Particle-Size Distributions. Forests 9: 1-16. https://doi. org/10.3390/f9040181
Riegler, M., 2019: Zustandserfassung von Forststraßen am Beispiel des Lehrforstes Rosalia [Maintenance status monitoring for forest roads demonstrated for the training forest Rosalia]. Master thesis, University of Natural Resources and Life Sciences, Vienna, Austria.

Rohrdorfer Sand und Kies GmbH, 2018: Preisliste 2018 [Prices 2018]. Available online: https://www.rohrdorfer.at/2510_ DE.pdf?exp=24581485844500 (accessed Jul 24, 2018)

Rohringer, O., 1992: Aus Steinen wird Grädermaterial [Stones turn to graded aggregate]. Österreichische Forstzeitung 103(4): 50-51.

Ryan, T., Phillips, H., Ramsay, J., Dempsey, J., 2004: Forest Road Manual. Guidelines for the design, construction and management of forest roads. COFORD, Dublin, Ireland, 170 p.

Sheehy, D.M.C., 2001: Reconditioning and stabilization of unpaved roads for reducing road maintenance and impacts on fisheries habitat. Proceedings of the 2001 International Conference on Ecology and Transportation, Keystone, Colorado, U.S.A., Sep 24-28. Irwin, C.L., Garrett, P., McDermott, K.P., Center for Transportation and the Environment, North Carolina State University, Raleigh, North Carolina, U.S.A., 121-131.

Stampfer, K., 1991: Straßenunterhalt in der Schweiz und Folgerungen für die Forststraßenerhaltung in Österreich [Road maintenance in Switzerland and consequences for forest road maintenance in Austria]. Vienna (Austria): Master thesis, University of Natural Resources and Life Sciences, Vienna, Austria.

Steinert, B.C., Humphrey, D.N., Kestler, M.A., 2005: Portable falling weight deflectometer study. Department of Civil and Environmental Engineering, University of Maine: Orono, U.S.A., 331 p.

Stooss, P., 1987: Bericht über den Einsatz eines mobile Steinbrechers [Report on the employment of a mobile stone crusher]. Schweizerische Zeitschrift für Forstwesen 138(7): 606-611.

TerraTest, 2009: Manual of the light falling weight deflectometer »TerraTest 3000«. TerraTest, Berlin, Germany, 80 p.

Uusitalo, J., 2010: Introduction to forest operations and technology. JVP Forest Systems Oy, Tampere, Finland, 287 p.

(C) 2020 by the authors. Submitted for possible open access publication under the terms and conditions of the Creative Commons Attribution (CC BY) license (http://creativecommons.org/licenses/by/4.0/). 
Authors' addresses:

Gernot Erber, PhD*

e-mail: gernot.erber@boku.ac.at

Huberta Kroisleitner, MSc

e-mail: huberta.kroisleitner@students.boku.ac.at

Thomas Varch, BSc

e-mail: thomas.varch@boku.ac.at

Prof. Karl Stampfer, PhD

e-mail: karl.stampfer@boku.ac.at

University of Natural Resources

and Life Sciences, Vienna

Department of Forest and Soil Sciences

Institute of Forest Engineering

Peter Jordan Strasse 82

1190, Vienna

AUSTRIA

Christoph Huber, PhD

e-mail: christoph.huber@bfw.gv.at

Austrian Research Centre for Forests

Forest Training Centre Traunkirchen

Department of Forest Engineering

Forstpark 1

4801, Traunkirchen

Received: February 20, 2020

AUSTRIA

Accepted: May 05, 2020

* Corresponding author 